Titulo do Trabalho

\title{
ESTUDO SOBRE A PEDRA FURADA EM VENTUROSA-PE NUMA PERSPECTIVA SISTÊMICA DA PAISAGEM GEOMORFOLÓGICA
}

Nome do Autor (a) Principal

Darla Juliana Cavalcanti Macedo

Nome (s) do Coautor (a) (s)

Jeovanes Lisboa da Silva Filho

Nome (s) do Orientador (a) (s)

Prof ${ }^{\mathrm{a}}$ Dra Maria Betânia Moreira Amador

Instituição ou Empresa

UNIVERSIDADE DE PERNAMBUCO - UPE/Campus Garanhuns

Instituição (s) de Fomento

CNPq - CONSELHO NACIONAL DE DESENVOLVIMENTO CIENTÍFICO E
TECNOLÓGICO

E-mail de contato

darlajuliana@hotmail.com

Palavras-chave

Paisagem turística, visão sistêmica, relações homem- lugar.

INTRODUÇÃO

O homem busca suas alternativas de vida e desenvolvimento do meio onde vive de diversas formas dentre as quais o aproveitamento turístico de um determinado lugar, quando este apresenta características que agradam de alguma maneira o ser humano. 
Nesse contexto, a paisagem geomorfológica da Pedra Furada no município de Venturosa-PE apresenta uma característica agradável aos olhos dos admiradores da natureza, que prezam uma paisagem de exuberância que pela mesma é proporcionada. Costa (2000) citado por Amador (2008, p. 81) relata que a estrutura rochosa em questão e caracterizada por "afloramentos rochosos, algumas vezes com aparência de matacões, de origem granítica, os quais aparecem em todas as partes na área, cujo exemplo mais conhecido é o enorme bloco em forma de arco conhecido como Pedra Furada". Através disso, e procurando-se fazer uma análise sistêmica da paisagem geomorfológica da Pedra Furada em relação ao homem e as características naturais que compõem o bioma caatinga o qual caracteriza o lugar em estudo, visa-se o entendimento de uma convivência harmoniosa sem que haja desequilíbrio e degradação ambiental, tendo-se sempre em mente que este é um processo que a cada dia se torna mais difícil devido ao ser humano apresentar quase sempre impulsos que levam a degradação do lugar que vive.

Logo, observa-se que não se evidencia a afetividade com o lugar como fica claro nas referencias de Yi-Fu Tuan em seu livro Topofilia (1980) e em vários outros autores que fazem relação a este tema. Sendo dessa forma, um pilar no que se refere às formas de percepção e sentimento que cada ser desenvolve pelo seu lugar cabendo aqui considerar reflexões sobre espaço e lugar de Tuan contida em outro livro seu intitulado Espaço e lugar (2013, p. 14):

$\mathrm{Na}$ experiência, o significado de espaço frequentemente se funde com o lugar. "Espaço" e mais abstrato do que "lugar". O que começa como espaço indiferenciado transforma-se em lugar a medida que o conhecemos melhor e o dotamos de valor.

Quando se fala sobre "homem" pode-se trazer a tona a grande importância que seus sentidos podem the proporcionar e, quando a intenção é voltada para a paisagem fica mais evidente que o sentido que mais proeminente é o da visão.

Dos cinco sentidos tradicionais, o homem depende mais conscientemente da visão do que dos demais sentidos para progredir no mundo. Ele é 
predominantemente um animal visual. Um mundo mais amplo se the abre e muito mais informações, que é espacialmente detalhada e especifica, chega até ele através dos olhos, do que através dos sistemas sensoriais da audição, olfato paladar e tato. A maioria das pessoas, provavelmente considera a visão como sua faculdade mais valiosa e preferia perder uma perna ou tornar-se surda ou muda a sacrificar a visão (TUAN 1980, pag. 7).

No intuito de trazer essa citação para a área da paisagem turística pode-se afirmar que a visão torna-se o ponto mais importante quando se objetiva fazer uma análise de como o homem vê a Pedra Furada e a percebe como espaço e lugar.

Ademais, salienta-se que a Pedra Furada também é um patrimônio do município de Venturosa. Embora tenha sido tombada na década de 1980, ao que tudo indica, continua sem receber o devido valor por parte da população do município e circunvizinha, principalmente.

\section{OBJETIVO GERAL}

- Analisar com abordagem sistêmica a paisagem geomorfológica da Pedra Furada em Venturosa-PE, visando um melhor entendimento de sua sustentabilidade com base no embasamento rochoso e sua relação com meio ambiente.

\section{OBJETIVOS ESPECÍ́FICOS}

- Descrever as características geomorfológicas do Município com base em observações colhidas no ato da pesquisa bibliográfica e de campo de forma a tornar clara e objetiva os aspectos a serem observados.

- Verificar a dinâmica da paisagem no entorno da Pedra Furada frente á fauna e a flora local.

- Destacar benefícios que este ponto turístico traz para o município. 
- Identificar percepções de moradores e do setor público em relação à Pedra Furada

\section{METODOLOGIA}

A metodologia do projeto está fundamentada, primeiramente, nas pesquisas bibliográficas disponíveis sobre o tema em pauta. Na sequencia, está-se realizando a pesquisa de campo registrando-se com fotografias e anotações das informações pertinentes ao tema, ao mesmo tempo em que se contribui com o levantamento morfodinâmico do geossistema onde se localiza a Pedra Furada no Município de Venturosa-PE (Figura 1) em consonância com o projeto ao qual esta pesquisa esta vinculada.

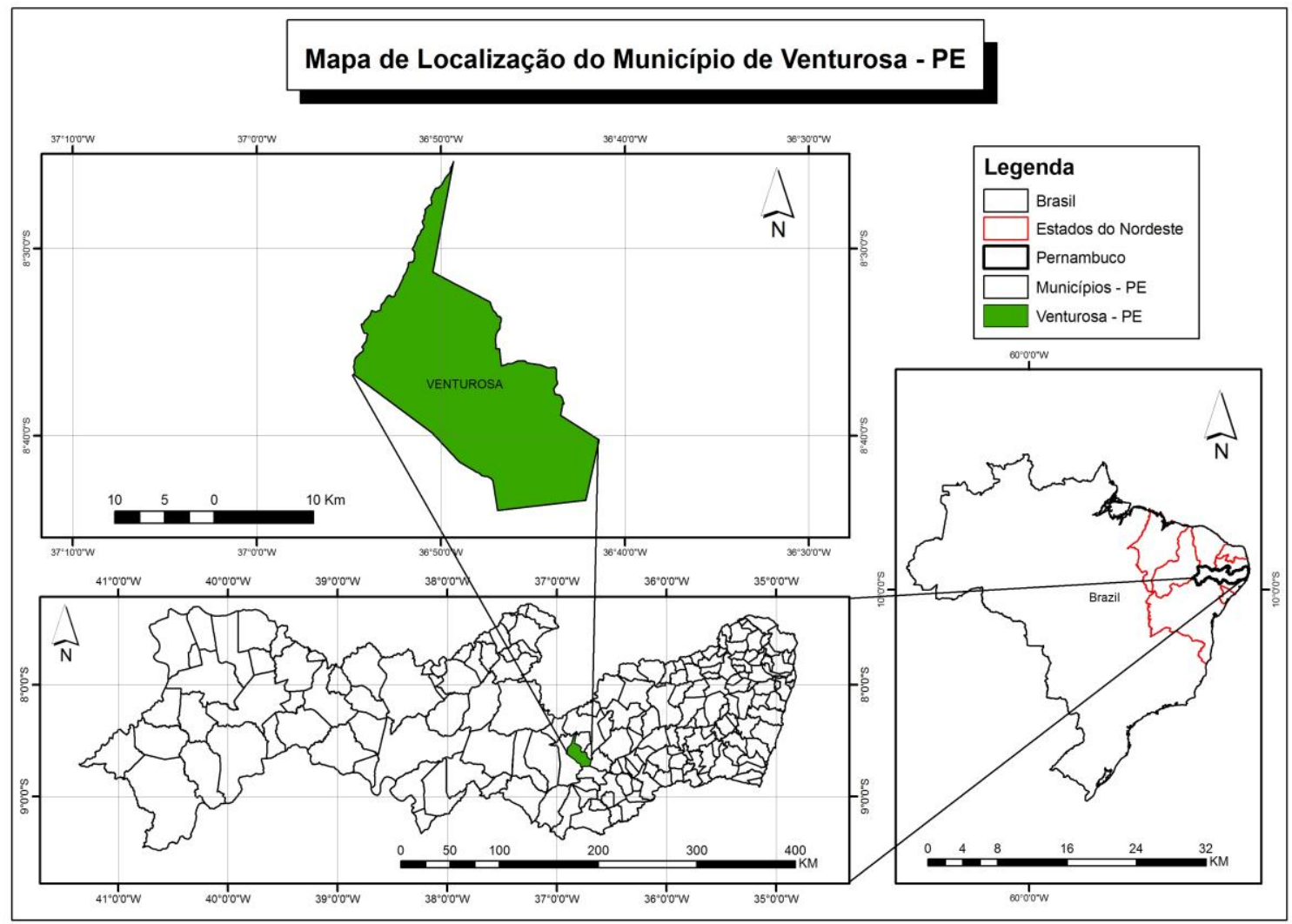

Figura 1: Mapa de localização do município de Venturosa, adaptado por Darla Macedo, 2013. 
Também se está fazendo tomadas de entrevistas e aplicação de formulários para colher dados importantes ao entendimento da questão. Por fim, proceder-se-á a analise das informações colhidas permitindo, assim, apresentar-se em relatórios parcial e final os resultados obtidos com a pesquisa intitulada de Estudo Sobre a Pedra Furada Numa Perspectiva Sistêmica Da Paisagem Geomorfológica em Venturos-PE.

\section{RESULTADO (S)}

Os resultados até aqui alcançados são de caráter referentes à pesquisa bibliográfica, visto que a pesquisa em destaque se encontra em fase inicial, e ainda tem resultados preliminares.

Destacando-se que a Pedra Furada faz parte de um conjunto de paisagens com potencialidade turística, uma vez que embeleza a região e o lugar acrescido do fato de pertencer a uma área em meio a caatinga com vegetação típica do lugar.

\section{CONSIDERAÇÕES FINAIS}

Os estudos bibliográficos até aqui desenvolvidos levam a considerar como foco de pesquisa a riqueza geomorfológica que a área em estudo apresenta. Sendo assim, busca-se concentrar esforços na utilização do sistemismo para o entendimento da complexidade presente na área e na percepção das relações homem-natureza, tão importantes para o desenvolvimento de toda e qualquer área onde o principal foco é a harmonia do meio ambiente, também com ser humano, este se apresentando como ser pensante que deve sempre procurar formas de preservar o meio onde vive.

Mais que as relações de beleza que um lugar apresenta, deve-se ter a percepção que a beleza se não for preservada e bem cuidada, mesmo tratando-se de um embasamento rochoso que pode ser danificado e, por isso precisa ser preservado e conservado. 


\section{REFERÊNCIAS}

AMADOR, Maria Betânia Moreira. Sistemismo e sustentabilidade: questão interdisciplinar. São Paulo: Scortecci, 2011.

A visão Sistêmica e sua contribuição ao estudo do espaço pecuário de Venturosa e Pedra no Agreste de Pernambuco. São Paulo: Blucher Acadêmico, 2008.

ARBEX Júnior, José; BACIC OLIC, Nélson. O Brasil em regiões: Nordeste. São Paulo: Moderna, 1999 (Coleção polêmica).

CASTRO, Cláudio de: JATOBÁ, Lucivânio. Litosfera: minerais, rochas, relevo. 2 ed. Recife: Bagaço, 2006.

IMAGENS DA PEDRA FURADA EM VENTUROSA - PE.: Disponível em: http://www2.uol.com.br/JC/sites/7maravilhas/pedra-furada.html. Acesso em 22 Maio 2014.

MACEDO, D. J. C. ; RODRIGUES, R. R. V. ; AMADOR, Maria Betânia Moreira . O JUAZEIRO (Zizyphus joazeiro Mart) NO CONTEXTO RURAL DO MUNICÍPIO DE VENTUROSA-PE. In: IX Fórum Ambiental da Alta Paulista, 2013, Tupã/SP. Periódico Eletrônico Fórum Ambiental da Alta Paulista. Tupã/SP: ANAP, 2013. v. 9. p. 175-180.

MORIN. Edgar. Introdução ao pensamento complexo. Tradução de: Eliane Lisboa. Porto Alegre: Sulina 2005.

TUAN, Yi-Fu. Topofilia. Um estudo da percepção, atitudes e valores do meio ambiente. São Paulo: DIFEL, 1980.

2013.

. Espaço e lugar: a perspectiva da experiência. Traducao de Livia de Oliveira. Londrina: Eduel, 